\title{
PA-1, a novel synthesized pyrrolizidine alkaloid, inhibits the growth of Escherichia coli and Staphylococcus aureus by damaging the cell membrane
}

\author{
$\mathrm{Na} \mathrm{Li}^{1,4}$, Sheng-nan $\mathrm{Tan}^{1,4}$, Jian $\mathrm{Cui}^{2}$, Na Guo${ }^{1}$, Wei Wang ${ }^{1}$, Yuan-gang $\mathrm{Zu}^{1}$, Shuang Jin ${ }^{1}$, Xian-xiu Xu ${ }^{3}$, \\ Qun $\mathrm{Liu}^{3}$ and Yu-jie Fu${ }^{1}$
}

In the present study, antimicrobial activity and mode of a novel synthesized pyrrolizidine alkaloid (PA-1) were investigated. PA-1 exhibited predominantly strong antibacterial activity toward six bacteria tested with minimal inhibitory concentration (MIC) values ranging from 0.0039 to $0.025 \mathrm{mg} \mathrm{ml}^{-1}$. The time-kill assay indicated that PA-1 killed Escherichia coli and Staphylococcus aureus completely at $2 \mathrm{MIC}$ (minimum bactericidal concentration) within $8 \mathrm{~h}$. Besides, PA-1-induced death rates of most sensitive strains ( $E$. coli, $97.80 \%$ and $S$. aureus, $96.24 \%$ ) were analyzed by flow cytometry. A combination of approaches was used to verify the membrane damage of $E$. coli and S. aureus. Results showed that release of $260 \mathrm{~nm}$ absorbing materials quickly increased after PA-1 treatment. PA-1 also rapidly promoted the uptake of crystal violet from 24.52 to $97.12 \%$ for $E$. coli and from 19.68 to $97.63 \%$ for S. aureus when the concentrations were changed from MIC to 4 MIC. Furthermore, the cellular membrane damages were testified by the significant increase of fluorescence intensity and decrease of membrane potential. Finally, lecithin and phosphate groups were applied to search the possibly targets on the cytoplasmic membrane. Results showed that PA-1 acted on cytoplasmic membrane phospholipids and phosphate groups of $S$. aureus but not of $E$. coli. In conclusion, the novel synthesized PA-1 exerted its antibacterial activity by acting on membrane phospholipids and phosphate groups and then damaging the structures of cellular membrane, which finally led to cell death.

The Journal of Antibiotics (2014) 67, 689-696; doi:10.1038/ja.2014.49; published online 4 June 2014

\section{INTRODUCTION}

Bacterial diseases can result in many serious or life-threatening complications, such as blood poisoning (bacteremia), kidney failure and toxic shock syndrome. Escherichia coli and Staphylococcus aureus represent exemplary model organisms for Gram-negative and Grampositive bacteria that can induce numerous diseases. ${ }^{1,2}$ Broadspectrum antimicrobial agents can eradicate these diseases, but can also result in drug resistance and severe side effects. ${ }^{3}$

Pharmacologically, alkaloids represent one of the most important classes of nitrogenous compounds with organic heterocyclic ring, possessing antibacterial, antifungal, insecticidal, antiviral, anticancer, antimalarial, antiinflammatory and antiaging activities. ${ }^{4}$ For example, berberine and ephedrine are effective to cure bacterial and inflammatory infections and asthma. ${ }^{5,6}$ Depending on the different compositions and structures of compounds, alkaloids can be classified as pyrrolizidine alkaloid (PA-1), quinoline alkaloid, indole alkaloid, quinazolone alkaloid and so on.
PA-1, which own antibacterial activity, act as a constitutive plant defense mechanism and form a large group of plant secondary chemicals. ${ }^{7}$ However, the occurrence of human abuse, environmental pollution and changes of climate has resulted in the sharp decrease of natural resource. Therefore, biosynthesis, semisynthesis and total synthesis of PA-1 are in the center of interest. It is desirable to develop a new strategy for the efficient construction of the azabicyclic skeleton from simple acyclic starting materials in a single step. ${ }^{8}$ An organocatalytic domino reaction of 1,4-dien-3-ones with ethyl isocyanoacetate that allowed the formation of three $\mathrm{C}-\mathrm{C}$ and one $\mathrm{C}-\mathrm{N}$ bonds in a regio- and diastereoselective manner in a single reaction were used to synthesize a series of novel PA-1. PA-1, which showed strong antibacterial activity, was used to systematically study the antibacterial mechanism of PA-1 derivatives, providing a novel antibacterial drug candidate.

\footnotetext{
${ }^{1}$ Engineering Research Center of Forest Bio-Preparation, Ministry of Education, Northeast Forestry University, Harbin, People's Republic of China; ${ }^{2}$ College of Life Sciences, Northeast Forestry University, Harbin, People's Republic of China and ${ }^{3}$ Department of Chemistry, Northeast Normal University, Changchun, People's Republic of China Correspondence: Professor Y-j Fu, Key Laboratory of Forest Plant Ecology, Ministry of Education, Northeast Forestry University, Box 332, Hexing Road 26, Harbin 150040, People's Republic of China.

E-mail: yujie_fu@163.com

${ }^{4}$ These authors contributed equally to this work.

Received 31 July 2013; revised 4 March 2014; accepted 3 April 2014; published online 4 June 2014
} 


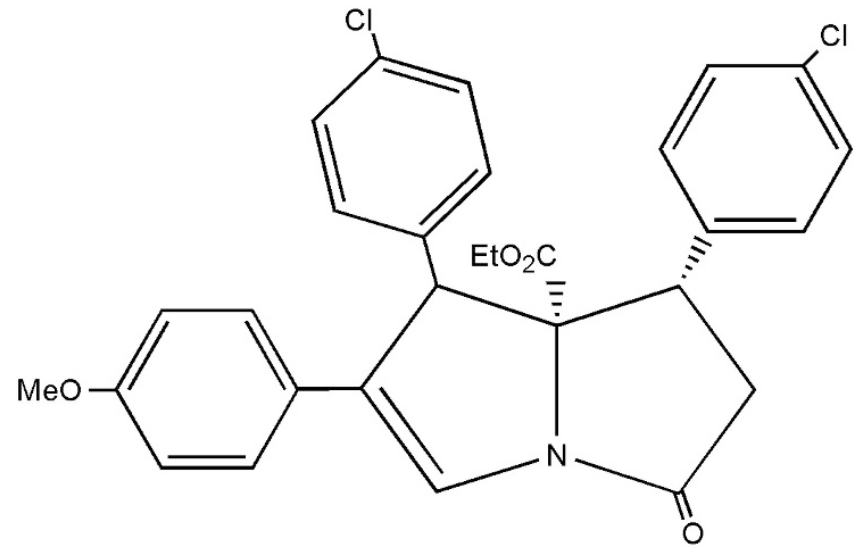

Figure 1 The chemical structure of a novel synthesized pyrrolizidine alkaloid (PA-1).

The aim of this work was to investigate the antimicrobial activity and mechanism of a novel PA-1 (Figure 1), which was synthetized by organocatalytic domino reaction. ${ }^{9}$ Minimal inhibitory concentration (MIC) and minimum bactericidal concentration (MBC) values of PA1 were determined against eight microorganisms. The time-kill kinetics of E. coli and S. aureus treated with PA-1 were also studied. In addition, flow cytometry (FCM) was used to test the inhibition rates of E. coli and S. aureus. The cell integrity measurement, crystal violet assay, fluorescence microscopy assay and membrane potential (MP) analyses were carried out to analyze changes of membrane permeability. To find the targets on cytoplasmic membrane, the effects of lecithin and phosphate groups on the antibacterial activity of PA-1 were investigated.

\section{MATERIALS AND METHODS}

\section{Materials}

PA-1 (purity > 99\%) was provided by Department of Chemistry, Northeast Normal University, China. Penicillin, chloramphenicol and erythromycin (all purity $>99 \%$ ) were used as positive control and were purchased from the Sigma Chemical (St Louis, MO, USA). Propidium iodide (PI), crystal violet and 3, 3'-dihexyloxacarbocyanine iodide were obtained from Sigma Chemicals (Shanghai, China). Yolk lecithin was purchased from Sigma Chemicals.

\section{Microorganisms and culture conditions}

S. epidermidis (ATCC 12228), S. aureus (ATCC 6538), Bacillus subtilis (ATCC 6633), E. coli (ATCC 8739), Proteus vulgaris (ATCC 49132), Pseudomonas aeruginosa (ATCC 27853), Aspergillus niger (ATCC 16404) and Candida albicans (ATCC 10231) were obtained from the Institute of Applied Microbiology, Heilongiiang Academy of Science (China). They were maintained on an agar slant at $4{ }^{\circ} \mathrm{C}$ and cultured on nutrient agar or potato dextrose agar at 37 or $25^{\circ} \mathrm{C}$ for $24 \mathrm{~h}$.

\section{Antimicrobial activity}

Bacterial cells $\left(10^{5} \mathrm{CFU} \mathrm{ml}{ }^{-1}\right)$ were inoculated into a nutrient broth at $0.1 \mathrm{ml}$ per well, in 96-well microtiter plates. MICs were determined by microtiter broth dilution method based on the guidelines in the literature. ${ }^{10}$ The stock solution of PA-1 was $1 \mathrm{mg} \mathrm{ml}^{-1}$ in $0.5 \%$ dimethyl sulfoxide and the required concentrations for experiments were prepared from this. After $24 \mathrm{~h}$ of incubation at $37^{\circ} \mathrm{C}$, the minimal concentration of PA-1 to prevent the growth of the given test organisms was defined as MIC. Fungal cells $\left(10^{5} \mathrm{CFU} \mathrm{ml}{ }^{-1}\right)$ were inoculated in yeast extract peptone dextrose broth $(0.1 \mathrm{ml}$ per well) in microtiter plates. After the determination of MIC, $10 \mu \mathrm{l}$ mixtures from the wells with no growth were spread on agar plates for MBC determination. Penicillin, chloramphenicol and erythromycin were used as positive control. All determinations were performed by three independent assays.

\section{Time-kill dynamics}

Time-kill dynamics of E. coli and S. aureus treated with PA-1 (corresponding to control, $1 / 2 \times$ MIC, MIC and $2 \times$ MIC) were studied based on the number of viable cells determined through a colony-counting method in plates. ${ }^{11}$ Timekill curves were constructed by plotting $\log _{10} \mathrm{CFU} \mathrm{ml} l^{-1}$ against time (h). All the determinations above were done in triplicates.

\section{FCM analysis}

E. coli and S. aureus were cultured in a nutrient broth with aeration for $24 \mathrm{~h}$ at $37^{\circ} \mathrm{C}$. Different concentrations of PA-1 (corresponding to MIC and MBC) were added to cells for $8 \mathrm{~h}$. Untreated bacteria were used as control. Cells were collected by centrifugation at 8000 r.p.m. for $10 \mathrm{~min}$ at $25^{\circ} \mathrm{C}$, washed twice with phosphate-buffered saline buffer (50 mM; $\mathrm{pH} 7.0)$, and subsequently resuspended in phosphate-buffered saline to obtain a final concentration of $10 \log _{10} \mathrm{CFU} \mathrm{ml}{ }^{-1}$. Then, PI $\left(100 \mu \mathrm{g} \mathrm{ml}^{-1}\right)$ was added and incubated in the dark for $15 \mathrm{~min}$. Samples were measured by using the FL-3 channels of a FCM (Partec GmbH, PAS, Germany). The inhibition rates of PA-1-treated bacteria were determined according to the fluorescence intensity. ${ }^{12}$

\section{Membrane permeability}

Integrity of cell membrane. Cell membrane integrity of E. coli and S. aureus was examined by measuring the release of ultraviolet (UV)-absorbing materials at $260 \mathrm{~nm} .{ }^{13}$ Bacterial cultures grown in nutrient broth were collected by centrifugation at 8000 r.p.m. for $10 \mathrm{~min}$, washed and resuspended in $0.5 \%$ $\mathrm{NaCl}$ solution. Different concentrations of PA-1 (MIC and MBC) were added. Cells without PA-1 treatment were treated as control. The release of materials absorbing at $260 \mathrm{~nm}$ over time was monitored with a UV-visible spectrophotometer. All the measurements were done in triplicates.

Crystal violet assay. The alteration of membrane permeability of E. coli and S. aureus was investigated by crystal violet assay. ${ }^{14}$ Bacterial cultures grown in nutrient broth were collected by centrifugation at $9300 \mathrm{~g}$ for $5 \mathrm{~min}$, washed and resuspended in $0.5 \% \mathrm{NaCl}$ solution. PA-1 (1/2MIC, MIC, 2MIC and 4MIC) was added and incubated at $37^{\circ} \mathrm{C}$ for $8 \mathrm{~h}$. Control samples were prepared similarly without PA-1 treatment. Cells were collected at $9300 \mathrm{~g}$ for $5 \mathrm{~min}$ and then resuspended in $0.5 \% \mathrm{NaCl}$ solution containing $10 \mu \mathrm{g} \mathrm{ml} l^{-1}$ crystal violet. After incubated for $10 \mathrm{~min}$ at $37^{\circ} \mathrm{C}$, the suspension was then centrifuged at $13400 \mathrm{~g}$ for $15 \mathrm{~min}$ and the $\mathrm{OD}_{590}$ of the supernatant was measured by a UVvisible spectrophotometer. The OD values of the crystal violet initial solution used in the assay were investigated and considered as 100\%. All the determinations above were done in triplicates. The percentages of crystal violet uptake were calculated using the following formula: (OD value of the sample $) /(\mathrm{OD}$ value of crystal violet solution $) \times 100$.

Fluorescence microscopy assay. The red fluorescent nucleic acid stain (PI) was used to detect the damages of cell membrane. Three milliliters of the dye $\left(1 \mathrm{mg} \mathrm{ml}^{-1}\right.$ ) was added to $1 \mathrm{ml}$ bacterial suspension (treated by PA-1 at MIC and $\mathrm{MBC}$ ), mixed thoroughly and kept in the dark for $15 \mathrm{~min}$. Then, $10 \mu \mathrm{l}$ of the stained bacterial suspension was placed between a slide and a coverslip. A XSP-13 fluorescence microscope was used to observe the stained bacteria at a magnification of $\times 40$ and evaluate bacterial membrane integrity. ${ }^{15}$

Measurement of MP. 3, 3'-Dihexyloxacarbocyanine iodide was used to measure the changes of MP. ${ }^{16}$ E. coli and S. aureus cells were mixed with different concentrations of PA-1 (corresponding to MIC and MBC) and incubated for $8 \mathrm{~h}$. Untreated bacteria were used as control. Cells were subsequently collected and washed twice with phosphate-buffered saline buffer. Then suspensions were incubated with $0.5 \mu \mathrm{m} 3,3^{\prime}$ dihexyloxacarbocyanine iodide for $10 \mathrm{~min}$ in the dark and analyzed by FCM (PARTEC). All the tests were done in triplicates. 
Effect of lecithin and phosphate groups on the antibacterial activity Effect of lecithin on the antibacterial activity was determined as previously described. ${ }^{17}$ Yolk lecithin was dissolved in alcohol to prepare the lecithin solution. PA-1 was added with a mass ratio of 1:0.2, 1:1 and 1:5 to lecithin. The mixtures were magnetically stirred overnight and then kept under vacuum for $60 \mathrm{~min}$ to remove the alcohol. Two controls were used in this experiment. A defined amount of lecithin-untreated PA-1 was served as control I and the blank culture medium was treated as control II. Test and control groups were inoculated under aseptic conditions with $50 \mu \mathrm{l}$ of inocula of bacteria, and incubated at $37^{\circ} \mathrm{C}$ for $24 \mathrm{~h}$. Then, the turbidity of the cultured medium was measured using a UV-visible spectrophotometer at $610 \mathrm{~nm}$. Effect of phosphate groups on the antibacterial activity was measured in a similar way as that of lecithin. All determinations were performed in triplicates.

\section{RESULTS AND DISCUSSION}

Antimicrobial activities of PA-1

The antimicrobial activities of PA-1 were tested toward eight strains by microtiter broth dilution method. In the case of Gram-positive bacteria, MIC values of PA-1 were $0.0078,0.0039$ and $0.0156 \mathrm{mg} \mathrm{ml}^{-1}$ against $S$. epidermidis, $S$. aureus and B. subtilis, respectively. In the case of Gram-negative bacteria, MIC values were $0.0313 \mathrm{mg} \mathrm{ml}^{-1}$ against E. coli, $P$. vulgaris and $P$. aeruginosa. Furthermore, MIC values of PA-1 against fungi were 0.125 and $0.0625 \mathrm{mg} \mathrm{ml}^{-1}$ against $A$. niger and C. albicans, respectively (Table 1 ). MBCs of PA-1 were from 0.0078 to $0.0625 \mathrm{mg} \mathrm{ml}^{-1}$ against six tested bacteria. It could be inferred from our results that PA-1 markedly inhibited the growth of Gram-positive bacteria and was more effective to $S$. aureus. The MICs and MBCs of PA-1 toward all Gram-negative bacteria were the same. In comparison with penicillin as positive control, PA-1 showed comparative antimicrobial activity against $S$. epidermidis, S. aureus, A. niger and C. albicans. With regard to chloramphenicol, PA-1 possessed the comparative antimicrobial activity against almost all pathogens tested in the assay. Meanwhile, PA-1 had comparative antibacterial activity against $S$. epidermidis, $S$. aureus and higher antibacterial activity toward E. coli and B. subtilis when compared with erythromycin.

As we have known, alkaloid has been known to possess antimicrobial activity and alkaloid berberine inhibiting the growth of bacteria by damaging the cell membrane is a basic antibacterial mechanism. ${ }^{18}$ Both PA-1 and berberrine are alkaloids and our results showed that PA-1 possessed stronger activity to Gram-positive bacteria than Gram-negative bacteria and fungi, which was similar with berberine. These differences of antibacterial activity were probably due to differences on membrane structure and composition among Gram-positive bacteria, Gram-negative bacteria and fungi. ${ }^{19,20}$ In order to test whether an agent has bacteriostatic or bactericidal properties, it is necessary to study the potential action mode in vitro. On the basis of this, E. coli and S. aureus were chosen as the representative Gram-negative and Gram-positive bacteria for the research of antibacterial mechanism.

Effect of PA-1 on the death rate of E. coli and S. aureus

On the basis of the results of MIC and MBC assay, time-kill curves of E. coli and $S$. aureus in relation to time and drug concentration were obtained. As can be seen from Figure 2, three concentrations of PA-1 with 2MIC, MIC and 1/2MIC were tested for the ability to kill E. coli and $S$. aureus, within $24 \mathrm{~h}$. It showed that low concentrations of PA-1 were not sufficient to kill E. coil and S. aureus. At 2MIC (MBC), it had

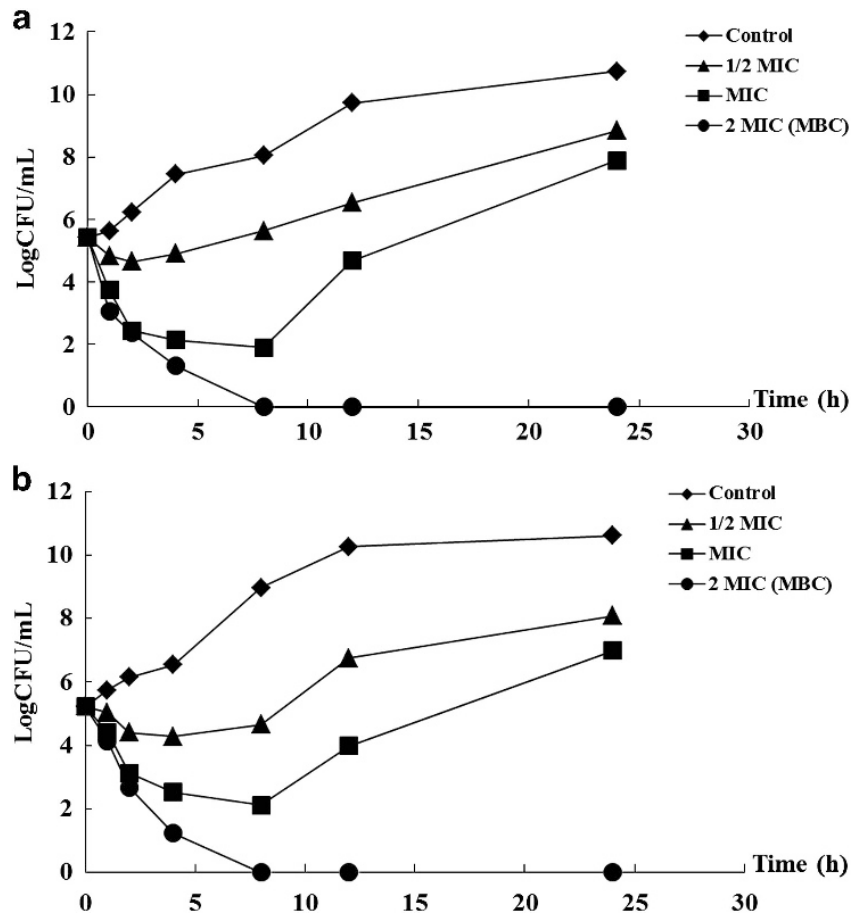

Figure 2 Time-kill kinetics of pyrrolizidine alkaloid (PA-1) against $E$. coli (a) and $S$. aureus (b). The concentrations used correspond to $1 / 2$ minimal inhibitory concentration) MIC, MIC and 2MIC (minimum bactericidal concentrations; $\mathrm{MBC}$ ); the control did not contain compounds or antibiotics.

Table 1 MICs and MBCs (mg ml ${ }^{-1}$ ) of PA-1 against microorganisms

\begin{tabular}{|c|c|c|c|c|c|c|c|c|}
\hline & $\mathrm{Se}$ & Sa & Bs & $E C$ & $P V$ & $\mathrm{~Pa}$ & $A n$ & $\mathrm{Ca}$ \\
\hline \multicolumn{9}{|l|}{ MIC } \\
\hline PA-1 & 0.0078 & 0.0039 & 0.0156 & 0.0313 & 0.0313 & 0.0313 & 0.125 & 0.0625 \\
\hline Penicillin & 0.0078 & 0.0078 & 0.0020 & 0.0020 & 0.0020 & 0.0020 & 0.25 & 0.0625 \\
\hline Chloramphenicol & 0.0039 & 0.0039 & 0.0078 & 0.0078 & 0.0625 & 0.0625 & $>1$ & 0.0625 \\
\hline Erythromycin & 0.0019 & 0.0019 & 0.125 & 0.125 & 0.0019 & 0.0010 & $>1$ & 0.0078 \\
\hline \multicolumn{9}{|l|}{$M B C$} \\
\hline PA-1 & 0.0313 & 0.0078 & 0.0625 & 0.0625 & 0.0625 & 0.0625 & $>1$ & $>1$ \\
\hline Penicillin & 0.5 & 0.5 & 0.125 & 0.125 & 1 & 0.5 & $>1$ & 1 \\
\hline Chloramphenicol & 0.0625 & 0.25 & 0.125 & $>1$ & 0.125 & 0.25 & $>1$ & 0.125 \\
\hline Erythromycin & 0.25 & 0.25 & 1 & 1 & 0.125 & 0.125 & $>1$ & 1 \\
\hline
\end{tabular}

Abbreviations: An, Aspergillus niger; Bs, Bacillus subtilis; Ca, Candida albicans; Ec, Escherichia coli; MBC, minimum bactericidal concentrations; MIC, minimum inhibitory concentration;

$\mathrm{Pa}$, Pseudomonas aeruginosa; PA-1, pyrrolizidine alkaloid; Pv, Proteus vulgaris; Sa, Staphylococcus aureus; Se, Staphylococcus epidermidis. 
a lethal effect and prolonged antibacterial activity within $8 \mathrm{~h}$ (Figure 2). Figure 2 also verified a significant concentration and time-dependent correlation for the bacteriostatic activity of PA-1 against both $E$. coil and S. aureus.

\section{FCM analysis}

Flow cytometric data were allowed to estimate the impact of PA- 1 on bacterial viability and cell membrane damage. After $8 \mathrm{~h}$ treatment, the dead cell fraction of E. coli increased from 3.60 to $97.80 \%$ with the increased concentration of PA-1 (Figures $3 \mathrm{a}$ and $\mathrm{b}$ ). The inhibition rates of $S$. aureus were 1.16, 61.68 and $96.24 \%$ for control, MIC and $\mathrm{MBC}$ treatment, respectively (Figures $3 \mathrm{c}$ and $\mathrm{d}$ ). These results were in general agreement with the time-kill dynamics shown in Figure 2. As far as we know, when cell membrane is damaged, PI that is a membrane-impermeable nucleic-acid fluorescent stain would be allowed to penetrate in and strongly fluoresces by binding to DNA and RNA. ${ }^{21}$ Bacteria in gate 4 that represented the membranedamaged cells were increased when the concentration of PA-1 was changed from MIC to MBC. Hence, membranes of E. coli and $S$. aureus were destroyed after PA-1 treatment and this was in accordance with the results of Paparella et al. ${ }^{22}$

\section{Effect of PA-1 on membrane permeability}

The antimicrobial activity of PA-1 against pathogenic bacteria has been reported, but no any action mode has been reported. For many antibacterial agents, the possible targets of action might be cell wall, cytoplasmic membrane, protein, nucleic acid and metabolic pathways. In order to further explore the antibacterial mode of PA-1 toward E. coil and S. aureus, membrane integrity measurement, crystal violet staining determination, fluorescence microscopy assay and MP analyses were used as methods for our investigation.

Effect of PA-1 on leakage of $260 \mathrm{~nm}$ absorbing materials from E. coli and $S$. aureus. As a structural component, the cytoplasmic cell membrane is an undoubted target for many antibacterial agents. If bacterial membrane became damaged, low-MW species such as $\mathrm{K}^{+}$ and $\mathrm{PO}_{4}{ }^{-}$would leach out first, and then followed by nucleotides such as DNA, RNA and other materials. These intracellular components are easily detected by the UV absorption at $260 \mathrm{~nm}$ as an emblem of membrane damage. ${ }^{23}$

Effect of PA-1 on leakage of $260 \mathrm{~nm}$ absorbing materials from E. coli and S. aureus was shown in Figure 4A. In case of E. coli, the suspension absorbance at $260 \mathrm{~nm}$ increased slowly over time and was almost unchanged after $12 \mathrm{~h}$ (Figure 4Aa). By comparison, the release rate of intracellular components increased as soon as PA-1 was mixed with $S$. aureus and increased abruptly to the maximum degree at $4 \mathrm{~h}$ (Figure $4 \mathrm{Ab}$ ). This result might probably attribute to the differences on membrane structure and composition of the two bacteria. Owing to the presence of lipopolysaccharide molecule, all Gram-negative bacteria possess an outer membrane that has a role as a drug barrier, a
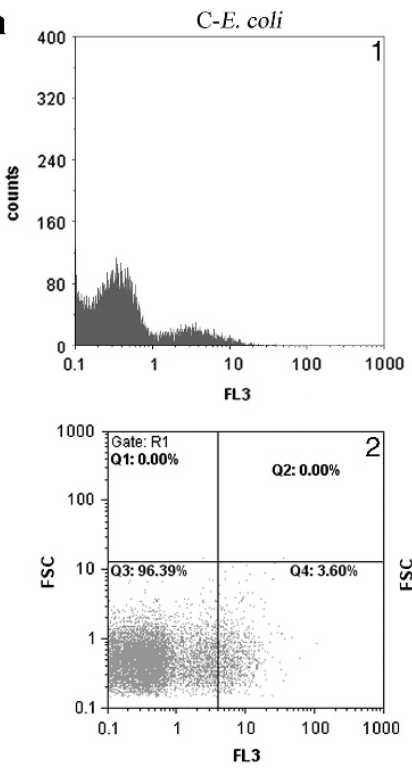
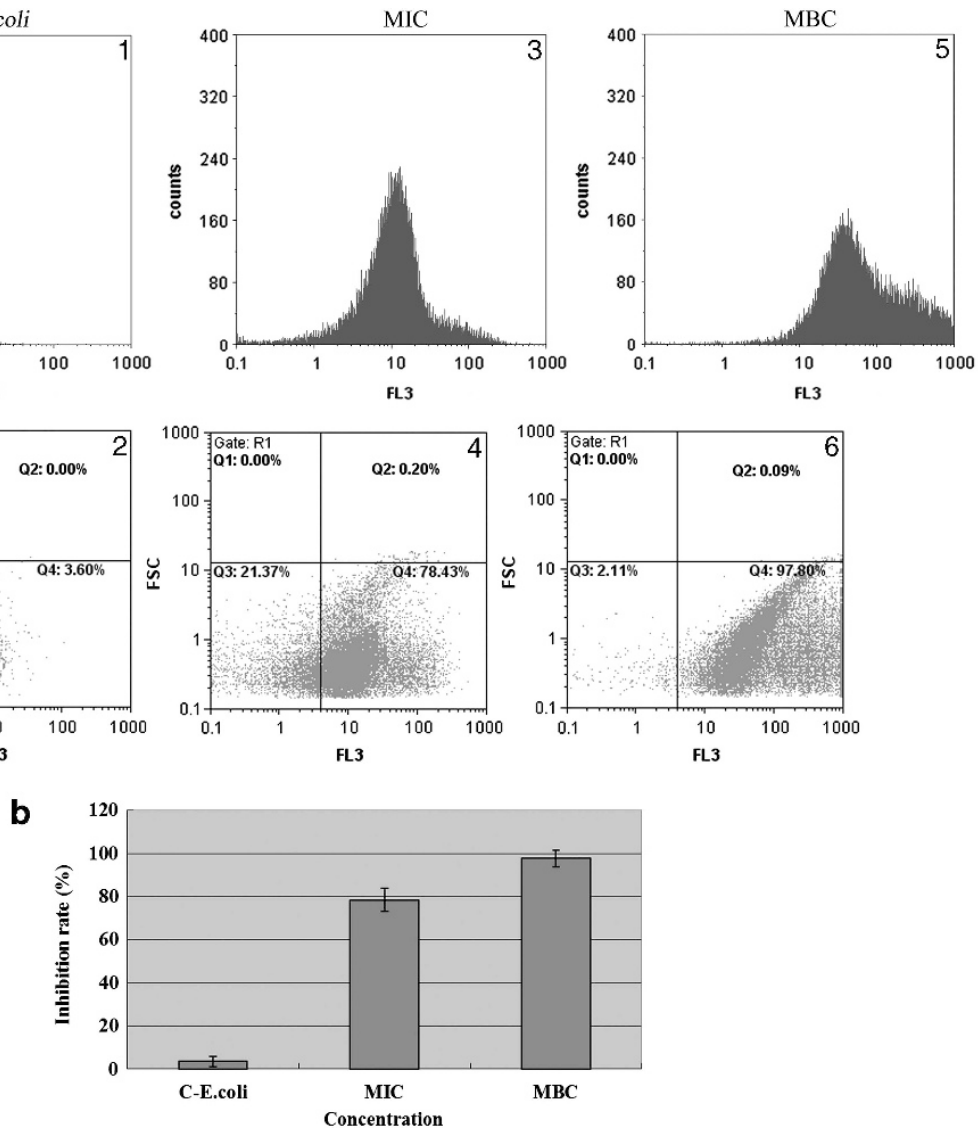

Figure 3 (a) Flow cytometry (FCM) histograms of E. coli grown in the presence of pyrrolizidine alkaloid (PA-1) stained with propidium iodide (PI). a1, a2: untreated control; a3, a4: treatment with minimal inhibitory concentration (MIC) PA-1; a5, a6: treatment with minimum bactericidal concentration (MBC) PA-1. (b) FCM histograms of E. coli grown in the presence of PA-1. (c) FCM histograms of S. aureus grown in the presence of PA-1 stained with propidium iodide (PI). c1, c2: untreated control; c3, c4: treatment with MIC PA-1; c5, c6: treatment with MBC PA-1. (d) FCM histograms of S. aureus grown in the presence of PA-1. A full color version of this figure is available at The Journal of Antibiotics journal online. 

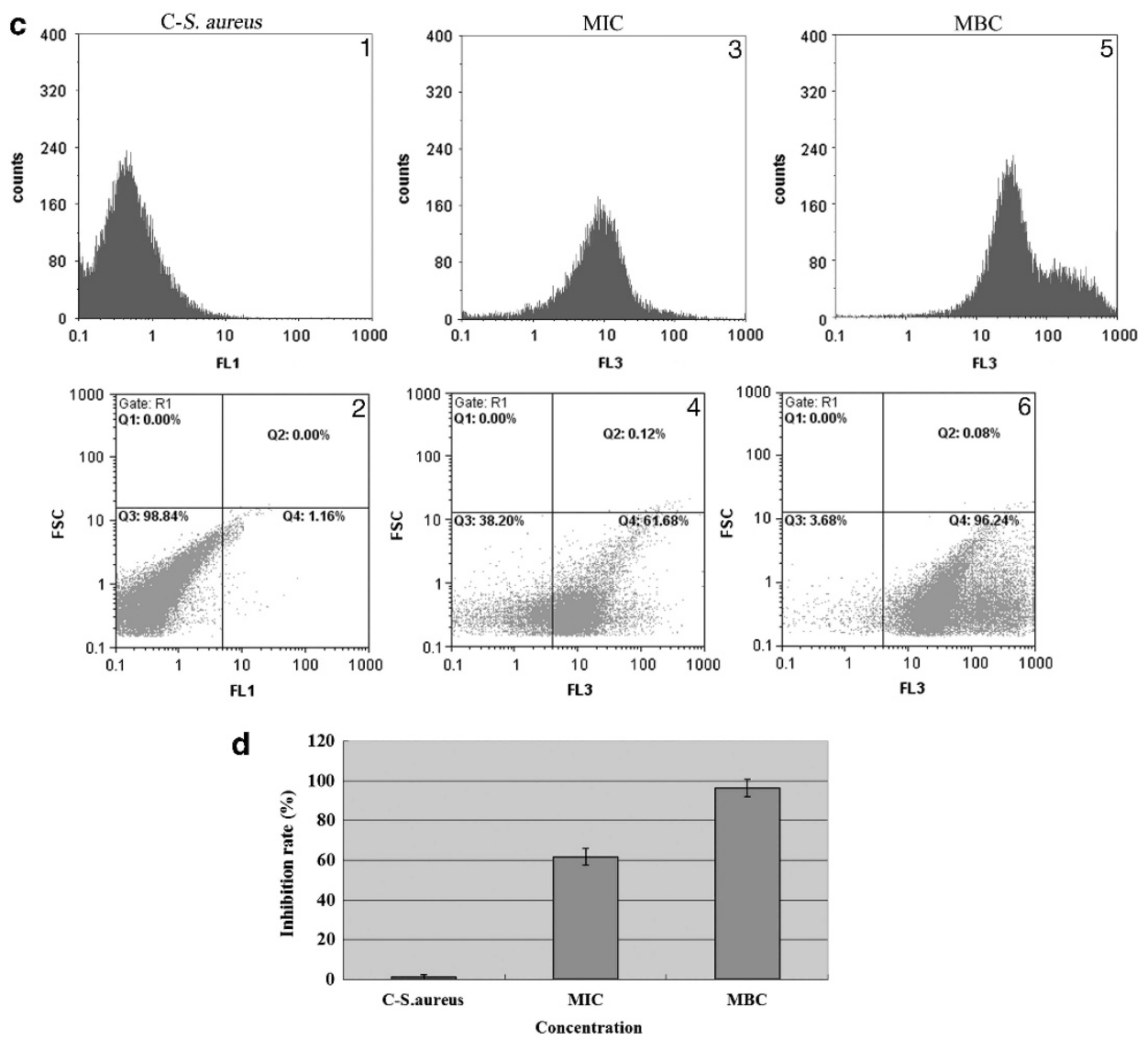

Figure 3 Continued.

whereas for the Gram-positive S. aureus, foreign molecules can enter the cell without difficulty because peptidoglycan layer of the cell wall is composed of networks with plenty of pores. ${ }^{24}$ In addition, at the same treatment time, $\mathrm{A}_{260}$ values of $E$. coli and $S$. aureus were higher at MBC than MIC. These results suggested that PA-1 damaged cytoplasmic membranes and caused subsequent leakage of intracellular constituents.

Effect of PA-1 on the alteration of membrane permeability of E. coli and $S$. aureus. Crystal violet penetrates the membrane poorly, but it enters easily as soon as the membrane is defective. ${ }^{25}$ The uptake of crystal violet by E. coli was $24.52 \%$ in the absence of PA-1 and increased up to 53.79 and $97.12 \%$ after MIC and 4MIC treatment, respectively. At the same time, crystal violet uptake of S. aureus increased from $19.68 \%$ in the absence of PA-1 to 67.61 and $97.63 \%$ after MIC and 4MIC treatment, respectively (Figure 4B). When compared with the control, a significant enhancement in the uptake of crystal violet was observed in E. coil and S. aureus after PA-1 treatment. This result demonstrated the changes of membrane permeability of PA-1treated E. coil and S. aureus.

Fluorescence microscopy analysis. The emission range of PI is 620$650 \mathrm{~nm}$ and PI-stained cells can emit red fluorescence light in green fluorescence light. Membrane damage induced by PA-1 was studied with fluorescence microscopy. As shown in Figure 4C, untreated E. coli and S. aureus showed weak red light fluorescence in green light emission. By comparison, stronger red light fluorescence was detected when the concentration of PA-1 was enhanced. To our knowledge, PI only penetrates bacteria with irreversibly damaged membranes and emits red fluorescence light. This parameter can provide a rough approximation of nonviable cells. Hence, it presented that membranes of $E$. coli and S. aureus were destroyed after PA- 1 treatment and this was in accordance with the former results.

Measurement of MP. MP, which only keeps in cytoplasmic membranes of bacteria, reflects membrane integrity and energy status as well as viability of cells. ${ }^{26}$ Prior results demonstrated the destructive effect of PA-1 on bacteria viability and membrane integrity. On the basis of this, we inferred that PA-1 might also affect MP of bacteria. The dye 3, 3'-dihexyloxacarbocyanine iodide, which can be bound to the inner side of cytoplasmic membrane bi-layer, ${ }^{27}$ was used in this study. Changes in the level of MP upon PA-1 treatment were measured by using flow cytometry. Fluorescence intensities of PA-1-treated cells were lower than the untreated controls and were concentration dependent (Figure 4D). Therefore, the decreased MP of cells treated by different concentrations of PA-1 was observed and demonstrated the reduced energy level of bacteria. As we have known, the loss of membrane integrity can result in the collapse of the cell energetics and active transports, and then lead to the death of the cell. ${ }^{28}$

\section{Effect of lecithin and phosphate on the antibacterial activity of} PA-1

As far as we know, the cytoplasmic membranes of E. coli and S. aureus were primarily composed of a bi-layer of phospholipid 

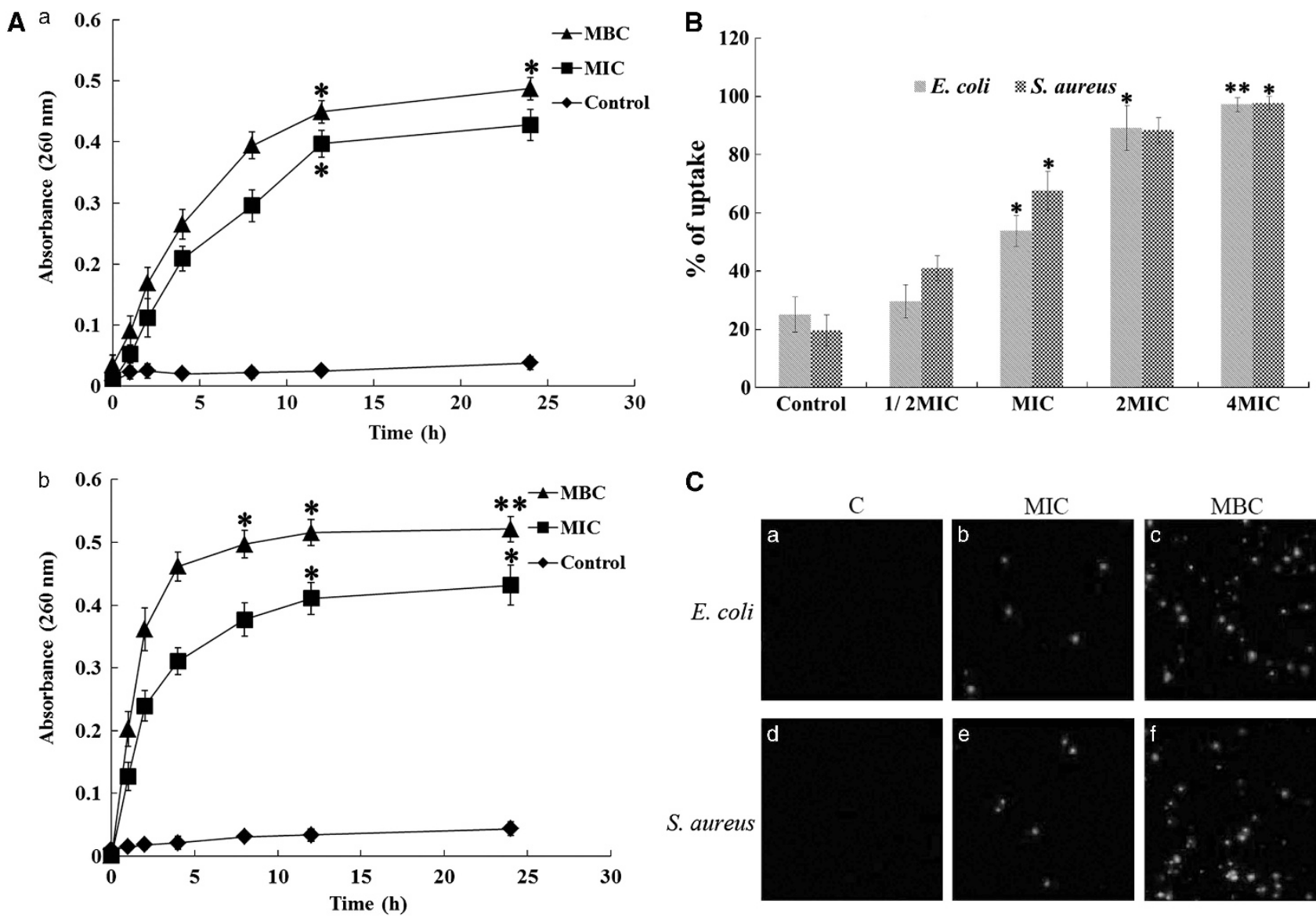

C
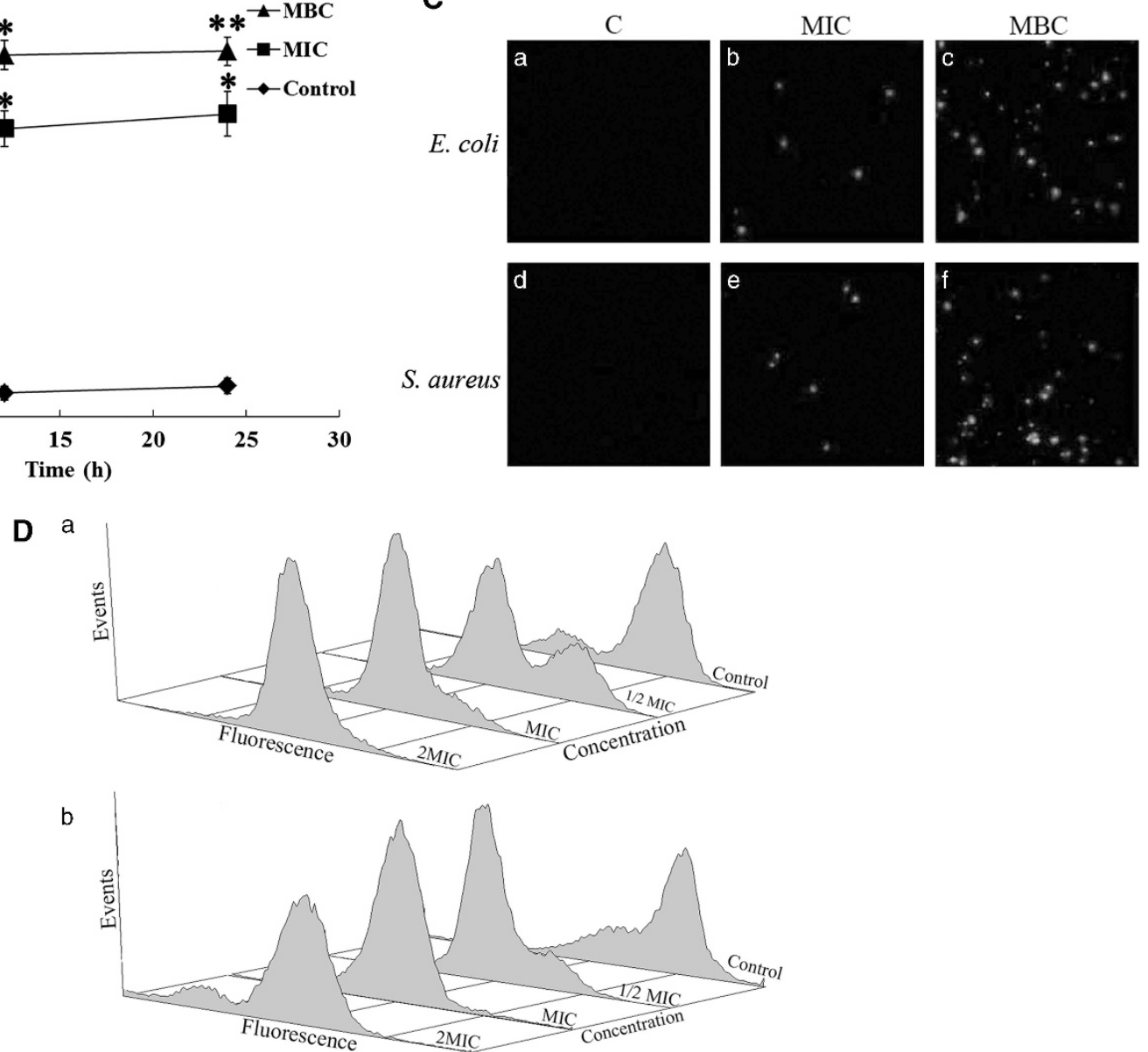

Figure 4 Effect of pyrrolizidine alkaloid (PA-1) on membrane permeability. (A) Presence of $260 \mathrm{~nm}$ absorbing material in the supernatants of E. coli (a) and S. aureus (b) treated with PA-1 (minimal inhibitory concentration; MIC and minimum bactericidal concentrations; MBC). The mean $\pm s . d$. for three replicates are illustrated. (B) Crystal violet uptake of PA-1 (1/2MIC, MIC, 2MIC, 4MIC) treated E. coli and S. aureus. The mean \pm s.d. for three replicates are illustrated. (C) Fluorescence microscopy of $E$. coli $(a-c)$ and $S$. aureus $(\mathrm{d}-\mathrm{f})$ and treated with PA-1. The fluorescence emission is in green light. (D) Analysis of $E$. coli (a) and S. aureus (b), collected at the exponential phase of growth and stained with the carbocyanine dye 3,3'-dihexyloxacarbocyanine iodide $\left(\mathrm{DiOC}_{6}\right)$ after treatment of PA-1. Abscissa 1: $\mathrm{DiOC}_{6}$-mediated fluorescence intensity, abscissa 2: the numbers indicated are related to increasing concentrations of PA-1, ordinate: cell counts. A full color version of this figure is available at The Journal of Antibiotics journal online.

molecules. Therefore, the phospholipid might notably become the target of PA-1 on the membrane. ${ }^{17}$ Lecithin was used to simulate phospholipid and test this hypothesis. As shown in Figure 5a, effect of lecithin on the antibacterial activity of PA-1 was measured by the inhibition rate. Results showed that PA-1 when treated with different concentrations of lecithin could still effectively inhibit growth of E. coli when compared with control. In the case of $S$. aureus, the addition of lecithin had an obvious effect on the inhibition rate. When the mass radio of PA-1 to lecithin was 1:0.2, the inhibition rate value was $75.2 \%$ and 

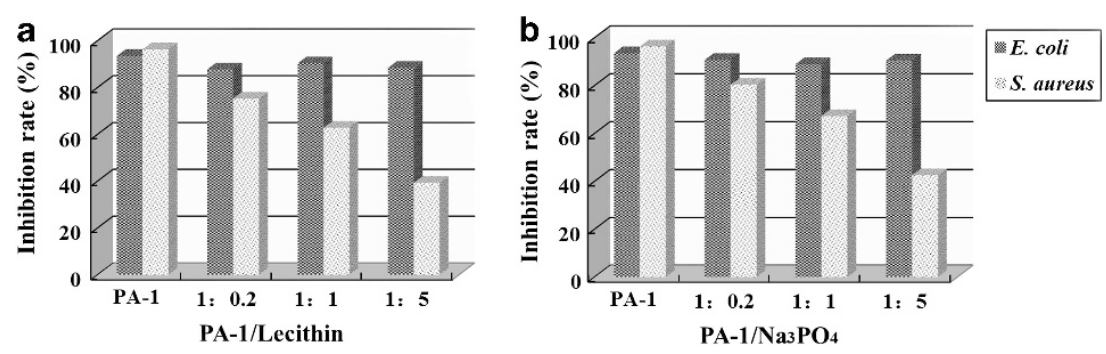

Figure 5 Effect of lecithin (a) and phosphate groups (b) on the antibacterial activity of pyrrolizidine alkaloid (PA-1) against E. coli and S. aureus. Assays were measured by the inhibition rate. The mass ratio of PA-1/lecithin or phosphate groups was 1:0.2, 1:1 and 1:5. Control was performed with lecithin/ phosphate group-untreated PA-1.

continued to decrease to 62.7 and $39.3 \%$ when the mass ratio varied to $1: 1$ and $1: 5$. It meant that lecithin influenced the interaction between PA-1 and $S$. aureus but it was not the case in E. coli. Therefore, the effect of lecithin on the antibacterial activity of PA-1 was completely different between E. coli and S. aureus. Phospholipid is the target molecule of PA-1 on the membrane of $S$. aureus but not of $E$. coli.

In addition, phosphate groups are components of nucleic acids (DNA and RNA) and phospholipid membranes, and they also have a key role in bacterial energy metabolism and regulation of acidbase balance. Therefore, phosphate groups were used to evaluate the possible involvement in antibacterial activity of PA-1 against E. coli and S. aureus. Compared with lecithin, similar results of phosphate groups on the antibacterial activity of PA-1 were shown in Figure 5b. For E. coli, PA-1 at tested concentrations with phosphate groups could inhibit bacterial growth normally when compared with the untreated PA-1. On the contrary, the addition of phosphate groups apparently weakened the inhibition rate of PA-1-treated S. aureus. These results suggested that phosphate groups influenced the interaction of PA-1 and S. aureus but not of E. coli.

For all we know, one of the major differences between E. coli and $S$. aureus is the existence of lipopolysaccharide, which only exists in the outer membrane of E. coli and can impede the penetration of charged and lipophilic compounds. ${ }^{29}$ Therefore, lipopolysaccharide may prevent PA-1 to bind to phospholipid and phosphate groups of Gram-negative bacteria, which was in accord with the results of $E$. coli. Although PA-1 did not act on phospholipid and phosphate groups of E. coli, proton motive force, electron flow, nutrient uptake and enzyme activity all might be the target of cell membrane according to Tian et al. ${ }^{30}$

In this study, antimicrobial activity and action mode of the novel synthesized PA-1 was firstly evaluated. It showed stronger antimicrobial activity against Gram-positive bacteria than against Gram-negative bacteria and fungi. The representative $E$. coil and $S$. aureus were chosen to investigate antibacterial mechanism. As for E. coli, the antibacterial activity of PA-1 was due to the interactions with cell membranes, and consequently influenced the membrane permeability and energy metabolism. Owing to the structural discrepancies between E. coil and S. aureus, results showed that PA-1 inhibited the growth of $S$. aureus by acting on phospholipids and phosphate groups of cell membranes and then damaging the cell membranes. However, we believe that the action mode of PA-1 is probably more complex than assumed above. Our future work will be focused on the mechanism of PA-1 to bacteria. Hopefully, PA-1 would be an alternative pro-drug with strong antibacterial activity to present antibiotics in the clinical usage.

\section{ACKNOWLEDGEMENTS}

We gratefully acknowledge the financial supports by National Natural Science Foundation of China (J1210053), Importation of International Advanced Forestry Science and Technology, National Forestry Bureau (2012-4-06) and Program for Special Fund of Forestry Industrial Research for Public Welfare of China (201004040).

1 Nyatoti, V. N., Shungu, S. M. \& Grace, R. Pathogenic Escherichia coli in traditional African weaning foods. Food Control. 8, 51-54 (1997).

2 Ray, G. T., Suaya, J. A. \& Baxter, R. Trends and characteristics of culture-confirmed Staphylococcus aureus infections in a large U.S. Integrated health care organization. J. Clin. Microbiol. 50, 1950-1957 (2012).

3 Waters, A. E. et al. Multidrug-resistant Staphylococcus aureus in US meat and poultry. Clin. Infect. Dis. 52, 1-4 (2011).

4 Reina, M. et al. Pyrrolizidine alkaloids from heliotropium megalanthum. J. Nat. Prod. 61, 1418-1420 (1998).

5 Boberek, J. M., Stach, J. \& Good, L. Genetic evidence for inhibition of bacterial division protein FtsZ by berberine. PLoS ONE 5, e13745 (2010).

6 Brooks, S. M., Sholiton, L. J., Werk, E. E. Jr \& Altenau, P. The effects of ephedrine and theophylline on dexamethasone metabolism in bronchial asthma. J. Clin. Pharmacol. 17, 308-318 (1977).

7 Singh, B., Sahu, P.M. \& Singh, S. Antimicrobial activity of pyrrolizidine alkaloids from Heliotropium subulatum. Fitoterapia 73, 153-155 (2002).

8 Tan, J., Xu, X., Zhang, L., Li, Y. \& Liu, Q. Tandem double-michael-addition/cyclization/ acyl migration of 1, 4-dien-3-ones and ethyl isocyanoacetate: stereoselective synthesis of pyrrolizidines. Angew. Chem. Int. Ed. Engl. 48, 2868-2872 (2009).

$9 \mathrm{Xu}, \mathrm{X} . \mathrm{X}$. et al. Direct synthesis of 6-azabicyclo[3.2.1]oct-6-en-2-ones and pyrrolizidines from divinyl ketones and observation of remarkable substituent effects. Adv. Synth. Catal. 353, 1218-1222 (2011).

10 Andrews, J. M. Determination of minimum inhibitory concentrations. J. Antimicrob. Chemother. 48, 5-16 (2001).

$11 \mathrm{Zu}$, Y. G. et al. Chemical composition of the SFE-CO2 extracts from Cajanus cajan (L.) Huth and their antimicrobial activity in vitro and in vivo. Phytomedicine 17, 1095-1101 (2010).

12 Li, L. R., Shi, Y. H., Su, G. F. \& Le, G. W. Selectivity for and destruction of Salmonella typhimurium via a membrane damage mechanism of a cellpenetrating peptide ppTG20 analogue. Int. J. Antimicrob. Agents 40, 337-343 (2012).

13 Zhou, K. et al. Mode of action of pentocin 31-1: an antilisteria bacteriocin produced by Lactobacillus pentosus from Chinese traditional ham. Food Control. 19, 817-822 (2008).

14 Vaara, M. \& Vaara, T. Outer membrane permeability barrier disruption by Polymixin in Polymixin-susceptible and resistant Salmonella typhimurium. Antimicrob. Agents Chemother. 19, 578-583 (1981).

15 Qi, A. Q., Qian, K. X., Shao, J. Z. \& Yan, Q. F. A fluorometry method to determine cell viability by double staining with fluorescein diacetate and propidium iodide. J. Cell Biol. 22, 50-53 (2000).

16 Ratinaud, M. H. \& Revidon, S. A flow cytometric method to assess functional state of the Listeria membrane. J. Microbiol. Methods 25, 71-77 (1996).

17 Xing, K., Chen, X. G., Liu, C. S., Cha, D. S. \& Park, H. J. Oleoyl-chitosan nanoparticles inhibits Escherichia coli and Staphylococcus aureus by damaging the cell membrane and putative binding to extracellular or intracellular targets. Int. J. Food Microbiol. 132, 127-133 (2009).

18 Jin, J. L., Hua, G. Q., Meng, Z. \& Gao, P. J. Antibacterial mechanisms of berberine and reasons for little resistance of bacteria. Chinese Herbal Med. 3, 27-35 (2010). 
19 Hirai, K., Aoyama, H., Irikura, T., lyobe, S. \& Mitsuhashi, S. Differences in susceptibility to quinolones of outer membrane mutants of Salmonella typhimurium and Escherichia coli. Antimicrob. Agents. Chemother. 29, 535-538 (1986).

20 Cho, J. \& Lee, D. G. The characteristic region of arenicin-1 involved with a bacterial membrane targeting mechanism. Biochem. Bioph. Res. Commun. 405, 422-427 (2011).

21 Ali, I. et al. In vitro antifungal activity of hydroxychavicol isolated from Piper betle L. Ann. Clin. Microbiol. Antimicrob. 9, 1-9 (2010).

22 Paparella, A. et al. Flow cytometric assessment of the antimicrobial activity of essential oils against Listeria monocytogenes. Food Control. 19, 1174-1182 (2008).

23 Je, J. Y. \& Kim, S. K. Antimicrobial action of novel chitin derivative. Biochim. Biophys Acta 1760, 104-109 (2006).

24 Tao, Y., Qian, L. H. \& Xie, J. Effect of chitosan on membrane permeability and cell morphology of Pseudomonas aeruginosa and Staphyloccocus aureus. Carbohydr. Polym. 86, 969-974 (2011).
25 Devi, K. P., Nisha, S. A., Sakthivel, R. \& Pandian, S. K. Eugenol (an essential oil of clove) acts as an antibacterial agent against Salmonella typhi by disrupting the cellular membrane. J. Ethnopharmacol. 130, 107-115 (2010).

26 Tian, F. et al. Antioxidant and antimicrobial activities of consecutive extracts from Galla chinensis: the polarity affects the bioactivities. Food Chem. 113, 173-179 (2009).

27 Müller, S., Loffhagen, N., Bley, T. \& Babel, W. Membrane-potential-related fluorescence intensity indicates bacterial injury. Microbiol. Res. 151, 127-131 (1996).

28 Nebe-Von Caron, G. \& Badley, R. A. Viability assessment of bacteria in mixed populations using flow cytometry. J. Microsc. 179, 55-66 (1995).

29 Schop, H., Wiese, M., Cordes, H. P. \& Seydel, J. K. Partial resistance of E. coli mutants against 2, 4-diamino-5-benzylpyrimidines by interactions with bacterial membrane lipopolysaccharides. Derivation of quantitative structure-binding relationships. Eur. J. Med. Chem. 35, 619-634 (2000).

30 Müller, S., Ullrich, S., Lösche, A., Loffhagen, N. \& Babel, W. Flow cytometric techniques to characterise physiological states of Acinetobacter calcoaceticus. J. Microbiol. Methods 40, 67-77 (2000). 